Karczewska Wiktoria. Expenditure on education and physical culture in the commune of Skulsk and Wilczyn in $2015-2018$. Comparative analysis. Journal of Education, Health and Sport. 2021;11(6):284-290. eISSN 2391-8306. DOI http://dx.doi.org/10.12775/JEHS.2021.11.06.031

https://apcz.umk.pl/czasopisma/index.php/JEHS/article/view/JEHS.2021.11.06.031

https://zenodo.org/record/5528800

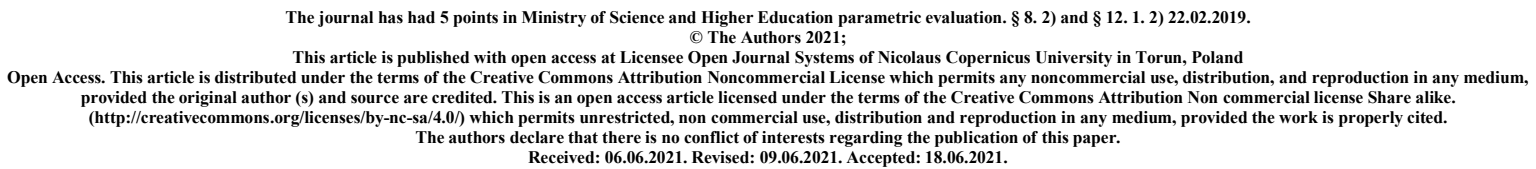

\title{
Expenditure on education and physical culture in the commune of Skulsk and Wilczyn in 2015-2018. Comparative analysis
}

\author{
Wiktoria Karczewska \\ ORCID iD: https://orcid.org/0000-0002-2844-3781 \\ Affiliation: State University of Applied Sciences in Konin \\ Country: Poland
}

Keywords: comparative analysis, municipal revenues, municipal expenditure, budget implementation

\begin{abstract}
According to the Constitution of the Republic of Poland of 1997, a commune is the basic unit of local selfgovernment. The commune realizes its own tasks and commissioned tasks, and its aim is cater to local residents needs. In both analyzed communes, the main source of expenditure were own tasks. In the balance sheet, the education department had the biggest share in the expenditure of both communes. In particular, these are expenses for kindergartens, primary schools, lower secondary schools and teachers' salaries. Expenditure on physical culture does not significantly affect the balance sheet of communes.
\end{abstract}

\section{Gmina jako jednostka samorządu terytorialnego}

Gmina, zgodnie z Konstytucją RP z 1997 roku, jest podstawową jednostką samorządu terytorialnego. Rozumiana jest jako wspólnota samorządowa, którą tworzą mieszkańcy. Gmina spełnia wszystkie zadania, które nie są zastrzeżone dla innych jednostek samorządu terytorialnego. Wykonuje zadania własne oraz zadania zlecone, a jej celem jest zaspokajanie potrzeb lokalnych mieszkańców.

Gminy są samorządowymi jednostkami podziału administracyjnego kraju, a ich władzę stanowi rada gminy. Władzę wykonawczą w gminach sprawuje wójt (w gminach wiejskich), burmistrz (w gminach miejsko-wiejskich i miejskich) lub prezydent (w dużych gminach miejskich). Występują trzy rodzaje gmin: gminy wiejskie, do których zalicza się wyłącznie 
tereny wiejskie; gminy miejsko-wiejskie, do których zalicza się zarówno obszar miasta jak i tereny wiejskie; gminy miejskie, do których zalicza się wyłącznie obszar miasta. Dnia 1 stycznia 2019 r. w Polsce istniało 1537 gmin wiejskich, 638 gmin miejsko-wiejskich oraz 302 gminy miejskie, w tym 66 gmin będących jednocześnie miastami na prawach powiatu.

\section{Wladze gminy i ich zadania}

Władze w gminie sprawuje rada gminy oraz wójt (burmistrz, prezydent miasta). Rada Gminy jest podstawowym organem samorządu gminnego, który wybierany jest poprzez wybory. Jest więc zasadniczą formą demokracji pośredniej w gminie.

Wójt jest organem wykonawczym. Zostaje on wyłoniony w powszechnych, równych, bezpośrednich wyborach, które odbywają się na zasadzie głosowania tajnego.

Tabela 1. Gmina jako organ jednostki samorządu terytorialnego

\begin{tabular}{|c|c|c|c|}
\hline Wyszczególnienie & Organ stanowiący & Organ kontrolny & Organ wykonawczy \\
\hline Gmina & Rada gminy & Rada gminy & $\begin{array}{c}\text { Wójt, burmistrz lub } \\
\text { prezydent }\end{array}$ \\
\hline
\end{tabular}

Źródło: opracowanie własne na podstawie B. Filipak, 2006, s. 17

Do właściwości rady gminy należą wszystkie sprawy pozostające w zakresie działania gminy, o ile ustawy nie stanowią inaczej. Do wyłącznej właściwości rady gminy należy m.in.: uchwalanie statutu gminy, ustalanie wynagrodzenia wójta, stanowienie o kierunkach jego działania oraz przyjmowanie sprawozdań z jego działalności, powoływanie i odwoływanie skarbnika gminy, który jest głównym księgowym budżetu - na wniosek wójta, uchwalanie budżetu gminy, rozpatrywanie sprawozdania z wykonania budżetu oraz podejmowanie uchwały w sprawie udzielenia lub nieudzielenia absolutorium z tego tytułu.

Do zadań wójta należy zaliczyć kierowanie bieżącymi sprawami gminy oraz reprezentowanie jej w sferze publiczno i prywatnoprawnej (Agustyniak, 2012). Oprócz tego wójt wykonuje uchwały rady gminy i zadania gminy, które są prawnie określone. Do tych zadań należy przede wszystkim: przygotowywanie projektów uchwał rady gminy, opracowywanie programów rozwoju w trybie określonym w przepisach o zasadach prowadzenia polityki rozwoju, określanie sposobu wykonywania uchwał, gospodarowanie mieniem komunalnym, wykonywanie budżetu, zatrudnianie i zwalnianie.

Dodatkowo do zadań wójta należy opracowanie planu operacyjnego ochrony przed powodzią, powiadamianie oraz odwoływanie pogotowia i alarmu przeciwpowodziowego. Szczególne zadania mogą przypadać na wójta w przypadku wprowadzenia stanu klęski żywiołowej. Wójt działa wówczas na zasadach określonych w odrębnych przepisach. 


\section{Budżet gminy}

Budżet stanowi „sformalizowane zestawienie dochodów i wydatków oraz przychodów i rozchodów jednostki sektora publicznego w formie planu finansowego, który zazwyczaj jest realizowany w okresie jednego roku" (Rudewicz, 2010).

Podstawy prawne dotyczące finansów gminnych określają według hierarchii następujące akty prawne: Konstytucja RP, w tym przede wszystkim ustawy, Ustawa z dnia 27 sierpnia 2009 roku o finansach publicznych, Ustawa z dnia 13 listopada 2003 roku o dochodach jednostek samorządu terytorialnego, Ustawa z dnia 8 marca 1990 roku o samorządzie gminnym, rozporządzenia oraz akty prawa miejscowego (Kosikowski, 2012).

Budżet jednostki samorządu terytorialnego pełni wiele różnych funkcji. Jedną z podstawowych jest funkcja kontrolna, która pozwala na weryfikację kierunków wydatkowania środków publicznych. Natomiast funkcja planistyczna, jako narzędzie planowania dochodów i wydatków wspomaga proces podejmowania decyzji oraz kierowane i realizowania lokalnej polityki (Rudewicz, 2010).

\section{Wydatki budżetowe gmin}

Najszerszym pojęciem dotyczącym wydatków są wydatki publiczne. Są one instrumentami polityki finansowej państwa, zwanej też polityką fiskalną. Dzięki nim władze publiczne mają możliwość prowadzenia działalności, która jest w ich obowiązkach i należy do ich funkcji (Denek E., Sobiech J., Wolniak J., 2010). Wydatki publiczne podzielone są według podstawowego kryterium, które wiąże się z funkcjami państwa i samorządu. Na przykład według szczebla ich wydatkowania podział jest następujący: wydatki szczebla centralnego (państwowe), wydatki szczebla regionalnego (państwowe, samorządowe, rządowo-samorządowe), wydatki szczebla lokalnego, do których zalicza się wyłączenie wydatki samorządowe (gmin i powiatów) (Owsiak S., 2017).

Najważniejsza część wydatków publicznych stanowią wydatki budżetowe, są to środki pieniężne wydatkowane z budżetów samorządowych oraz budżetu państwowego. Cechy, dzięki którym możliwe jest odróżnienie tych budżetów to m. in.: źródło, z którego pochodzą, funkcje tych wydatków, rola samorządów oraz rola parlamentu w ich ustalaniu, kontroli i dokonywaniu. Rodzaj i struktura wydatków budżetowych zależą od tego, jakie zadania podejmują samorządy oraz form organizacyjno-prawnych podmiotów samorządowych.

Istotnym podziałem wydatków publicznych, jest podział na: dotacje podmiotową, dotacje przedmiotową. Dotacja podmiotowa jest związana $\mathrm{z}$ całokształtem działalności danego podmiotu, a jej charakter jest ogólny. W dotacji przedmiotowej wydatkowane środki przeznaczone są na konkretny cel wydatkowania lub konkretną potrzebę. Przykładem tej 
dotacji są zadania zlecone (Owsiak S., 2017).Zadania zlecone gmina może wykonywać z zakresu administracji rządowej oraz organizacji przygotowań i przeprowadzania wyborów oraz referendów, zadania te nakładane są na gminu poprzez ustawy (Dz.U.1990 nr 16.poz.95).

\section{Charakterystyka gminy Skulsk i Wilczyn}

Gmina Skulsk jest gminą wiejską położoną w województwie wielkopolskim, w powiecie konińskim. Siedzibą gminy jest miejscowość Skulsk. Na dzień 31.12.2018 gminę Skulsk zamieszkiwało 6154 osób, z czego 3100 osób to mężczyźni, a 3054 osób to kobiety. Osób w wieku produkcyjnym było 3 781. Biorąc pod uwagę powierzchnie gminy, która wynosi $85 \mathrm{~km}^{2}$ oraz ilość osób zamieszkujących gminę, na $1 \mathrm{~km}^{2}$ przypadają 72 osoby.

Gmina Wilczyn jest jedną $\mathrm{z}$ mniejszych gmin położonych w województwie wielkopolskim, również w powiecie konińskim. Siedzibą gminy jest Na dzień 31.12.2018 r. gminę Wilczyn zamieszkiwało 6200 osób, spośród których 3089 z nich to mężczyźni, natomiast 3111 to kobiety. Najwięcej osób, bo ponad 4000 stanowią osoby w wieku produkcyjnym. Biorąc pod uwagę powierzchnię gminy, która wynosi $83 \mathrm{~km}^{2}$, na $1 \mathrm{~km}^{2}$ przypada 75 osób (GUS, 2020).

\section{Analiza wydatków gminy Skulsk i Wilczyn}

Na przestrzeni analizowanego okresu wydatki w gminie Skulsk wzrosły o prawie $40 \%$. Na wzrost ten wpłynął zarówno wzrost wydatków z zadań własnych, zadań zleconych oraz wydatków majątkowych. Zadania własne przyrosły o prawie $10 \%$, a ich udział zmniejszył się o około 15 punktów procentowych, zadania zlecone przyrosły o prawie 170\%. Największy przyrost wystąpił między rokiem 2015, a rokiem 2016.Ich udział zwiększył się z 17\% do prawie 33\%.Wydatki majątkowe wzrosły o około 30\%, a ich udział był stosunkowo niewielki i utrzymywał się na poziomie 6\% Szczegółowe dane zawarte zostały w tabelach na kolejnych stronach.

Tabela 2. Wykonanie i struktura wydatków w latach 2015-2018 w gminie Skulsk

\begin{tabular}{|c|c|c|c|c|c|c|c|c|}
\hline \multirow{2}{*}{ Rodzaj zadań } & \multicolumn{4}{|c|}{ Wykonanie } & \multicolumn{3}{|c|}{ Struktura w \% } \\
\cline { 2 - 9 } & $\mathbf{2 0 1 5}$ & $\mathbf{2 0 1 6}$ & $\mathbf{2 0 1 7}$ & $\mathbf{2 0 1 8}$ & $\mathbf{2 0 1 5}$ & $\mathbf{2 0 1 6}$ & $\mathbf{2 0 1 7}$ & $\mathbf{2 0 1 8}$ \\
\hline Zadania wlasne & 15302545 & 15055909 & 15736444 & 16696531 & 74,46 & 62,00 & 59,72 & 58,77 \\
\hline Zadania zlecone & 3524690 & 7995910 & 9463262 & 9446326 & 17,15 & 32,93 & 35,92 & 33,25 \\
\hline Wydatki majątkowe & 1725179 & 1232667 & 1149093 & 2265126 & 8,39 & 5,08 & 4,36 & 7,97 \\
\hline SUMA & 20552414 & 24284486 & 26348799 & 28407983 & 100,00 & 100,00 & 100,00 & 100,00 \\
\hline
\end{tabular}

Źródło: Opracowanie własne na podstawie sprawozdań gminy Skulsk 
Suma wydatków na przestrzeni analizowanego okresu wzrosła o 6\%. Najwyższy udział w wydatkach na zadania własne gminy Skulsk ma dział 801 oświata i wychowanie. Wydatki związane z tym działem to głównie wydatki związane z utrzymaniem szkół podstawowych, przedszkoli oraz gimnazjów. Udział tej pozycji w analizowanym okresie utrzymywał się na poziomie 53\%. Wartość wydatków działu 801 oświata i wychowanie w 2018 roku w stosunku do 2015 wzrosła o około 7\%. Pozostałe pozycje, w tym kultura fizyczna pomimo wysokiego wzrostu wartości, nie są istotne, ponieważ ich udziały w wydatkach własnych nie przekraczały $7 \%$.

Tabela 3. Wybrane elementy wykonanie planu wydatków gminy Skulsk

\begin{tabular}{|c|c|c|c|c|c|c|c|c|c|c|c|c|c|}
\hline \multirow{2}{*}{ Dzial } & \multirow{2}{*}{ DZIAL } & \multicolumn{3}{|c|}{ Rok 2015} & \multicolumn{3}{|c|}{ Rok 2016} & \multicolumn{3}{|c|}{ Rok 2017} & \multicolumn{3}{|c|}{ Rok 2018} \\
\hline & & $\begin{array}{l}\text { Plan } \\
\text { w zl }\end{array}$ & $\begin{array}{c}\text { Wykon. } \\
\text { w zl }\end{array}$ & Realiz. & $\begin{array}{l}\text { Plan } \\
\text { w zl }\end{array}$ & $\begin{array}{c}\text { Wykon. } \\
\text { w zl }\end{array}$ & Realiz. & $\begin{array}{l}\text { Plan } \\
\text { w zl }\end{array}$ & $\begin{array}{c}\text { Wykon. } \\
\text { w zl }\end{array}$ & Realiz. & $\begin{array}{l}\text { Plan } \\
\text { w zl }\end{array}$ & $\begin{array}{c}\text { Wykon. } \\
\text { w zl }\end{array}$ & Realiz. \\
\hline 801 & Oświata i wychowanie & $\begin{array}{l}\infty \\
\stackrel{\alpha}{ } \\
\stackrel{+}{\alpha} \\
\infty\end{array}$ & $\begin{array}{l}\underset{J}{J} \\
\infty \\
\hat{\sim} \\
\infty\end{array}$ & ڤั่ & $\begin{array}{l}\text { dे } \\
\text { a } \\
\dot{\sigma} \\
\infty\end{array}$ & $\begin{array}{l}0 \\
\infty \\
\infty \\
8 \\
\infty \\
\infty\end{array}$ & $\stackrel{\circ}{\dot{\alpha}}$ & \begin{tabular}{l}
$\infty$ \\
$\stackrel{D}{=}$ \\
\multirow{f}{0}{} \\
$\infty$
\end{tabular} & $\begin{array}{l}\stackrel{2}{I} \\
\frac{n}{2} \\
\infty\end{array}$ & ڤั & 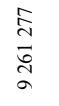 & $\begin{array}{l}\underset{+}{\ddagger} \\
\vec{\infty} \\
\infty \\
\infty\end{array}$ & $\stackrel{\circ}{\circ}$ \\
\hline 926 & Kultura fizyczna & 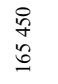 & $\begin{array}{l}\stackrel{2}{ } \\
\text { ஸे }\end{array}$ & $\stackrel{\circ}{\circ}$ & $\begin{array}{l}\mathbb{8} \\
\infty \\
\widetilde{V} \\
-1\end{array}$ & 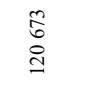 & $\stackrel{\circ}{\stackrel{\circ}{ }}$ & $\begin{array}{l}n \\
n \\
n \\
5 \\
n\end{array}$ & $\begin{array}{l}\stackrel{\curvearrowright}{R} \\
\stackrel{\infty}{=}\end{array}$ & $\stackrel{\circ}{\infty}$ & 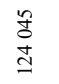 & $\begin{array}{l}\vec{\Xi} \\
\stackrel{\text { S }}{ }\end{array}$ & $\stackrel{\infty}{\grave{~}}$ \\
\hline
\end{tabular}

Źródło: Opracowanie własne na podstawie sprawozdań gminy Skulsk

Na przestrzeni analizowanego okresu wydatki w gminie Wilczyn wzrosły o prawie $70 \%$. $\mathrm{Na}$ wzrost ten wpłynął zarówno wzrost wydatków z zadań własnych, zadań zleconych oraz wydatków majątkowych. Zadania własne przyrosły o ponad 30\%, a ich udział zmniejszył się o około 17 punktów procentowych, zadania zlecone przyrosły o 165\%. Największy przyrost wystąpił między rokiem 2015, a rokiem 2016. Ich udział na przestrzeni analizowanego okresu zwiększył się o 8 punktów procentowych. Wydatki majątkowe wzrosły o około $221 \%$, a ich udział zwiększył się dwukrotnie, jednakże nie przekraczał $20 \%$.

Tabela 4. Wykonanie i struktura wydatków w latach 2015-2018 w gminie Wilczyn

\begin{tabular}{|c|c|c|c|c|c|c|c|c|}
\hline \multirow{2}{*}{ Rodzaj zadań } & \multicolumn{4}{|c|}{ Wykonanie } & \multicolumn{4}{|c|}{ Struktura w \% } \\
\hline & 2015 & 2016 & 2017 & 2018 & 2015 & 2016 & 2017 & 2018 \\
\hline Zadania własne & 18396015 & 17977457 & 20686306 & 24227547 & 76,12 & 64,07 & 59,56 & 59,35 \\
\hline Zadania zlecone & 3460754 & 7948600 & 9376288 & 9177951 & 14,32 & 28,33 & 27,00 & 22,48 \\
\hline Wydatki majątkowe & 2309703 & 2131165 & 4667853 & 7416535 & 9,56 & 7,60 & 13,44 & 18,17 \\
\hline SUMA & 24166472 & 28057222 & 34730447 & 40822033 & 100,00 & 100,00 & 100,00 & 100,00 \\
\hline
\end{tabular}

Źródło: Opracowanie własne na podstawie sprawozdań gminy Wilczyn 
Suma wydatków z zadań własnych na przestrzeni analizowanego okresu wzrosła o prawie $32 \%$. Największy udział miały wydatki z działu 801 oświata i wychowanie. Wydatki związane z tym działem to głównie wydatki związane $z$ utrzymaniem przedszkoli, szkól podstawowych oraz gimnazjów. W głównej mierze są to wynagrodzenia pracowników. W 2018 roku udział ten wynosił 34,5\%, na przestrzeni analizowanego okresu zmniejszył się o 10 punktów procentowych. Wartość tych wydatków spadła o 2\%. podobnie jak miało to miejsce w przypadku poprzedniej gminy, kultura fizyczna pomimo wzrostu wydatków, nie wpłynęła istotnie na bilans ogólny.

Tabela 5. Wybrane elementy wykonanie planu wydatków gminy Skulsk

\begin{tabular}{|c|c|c|c|c|c|c|c|c|c|c|c|c|c|}
\hline \multirow{2}{*}{ Dzial } & \multirow{2}{*}{ DZIAL } & \multicolumn{3}{|c|}{ Rok 2015} & \multicolumn{3}{|c|}{ Rok 2016} & \multicolumn{3}{|c|}{ Rok 2017} & \multicolumn{3}{|c|}{ Rok 2018} \\
\hline & & $\begin{array}{l}\text { Plan } \\
\text { w z zl }\end{array}$ & $\begin{array}{c}\text { Wykon. } \\
\text { w zl }\end{array}$ & Realiz. & $\begin{array}{l}\text { Plan } \\
\text { w zl }\end{array}$ & $\begin{array}{c}\text { Wykon. } \\
\text { w zl }\end{array}$ & Realiz. & $\begin{array}{l}\text { Plan } \\
\text { w zl }\end{array}$ & $\begin{array}{c}\text { wykon. } \\
\text { w zl }\end{array}$ & Realiz. & $\begin{array}{l}\text { Plan } \\
\text { w zl }\end{array}$ & $\begin{array}{c}\text { Wykon. } \\
\text { w zl }\end{array}$ & Realiz. \\
\hline 801 & $\begin{array}{c}\text { Oświata i } \\
\text { wychowanie }\end{array}$ & $\begin{array}{l}\text { 古 } \\
\text { à } \\
\text { g }\end{array}$ & 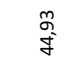 & 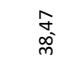 & $\begin{array}{l}\vec{n} \\
\text { f } \\
\text { m }\end{array}$ & $\begin{array}{l}\text { on } \\
\text { 岁 }\end{array}$ & $\begin{array}{l}\overrightarrow{\vec{n}} \\
\overbrace{\infty}\end{array}$ & $\begin{array}{l}\hat{0} \\
\text { ì } \\
\text { à }\end{array}$ & $\begin{array}{l}\vec{J} \\
\infty \\
\infty\end{array}$ & $\begin{array}{l}\stackrel{n}{2} \\
\text { g }\end{array}$ & 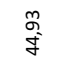 & $\underset{\substack{f \\
\infty \\
m}}{\infty}$ & $\begin{array}{l}\vec{n} \\
\text { f } \\
\text { nd }\end{array}$ \\
\hline 926 & $\begin{array}{l}\text { Kultura } \\
\text { fizyczna }\end{array}$ & $\stackrel{\substack{m \\
\sim}}{\sim}$ & $\underset{m}{\stackrel{t}{m}}$ & $\stackrel{\substack{m \\
m}}{n}$ & $\underset{m}{\stackrel{7}{m}}$ & $\underset{\infty}{F}$ & 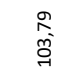 & $\begin{array}{l}\tilde{0} \\
0 \\
0 \\
0\end{array}$ & 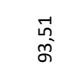 & $\stackrel{\infty}{\sim}$ & $\underset{m}{\stackrel{N}{m}}$ & $\stackrel{\infty}{m}$ & $\underset{m}{7}$ \\
\hline
\end{tabular}

Źródto: Opracowanie własne na podstawie sprawozdań gminy Wilczyn

\section{Zakończenie}

$\mathrm{Na}$ przestrzeni analizowanego okresu wartość wydatków z zadań zleconych, zadań własnych oraz wydatków majątkowych obu gminach wzrosła. Dynamicznego wzrostu wydatków, nie należy interpretować pozytywnie, jednostka powinna dążyć do ich redukcji, jednakże przy dynamicznym wzroście dochodów, dynamiczny wzrost wydatków można uznać za uzasadniony. W tym przypadku gmina Wilczyn powinna jednak zwrócić uwagę na źródła wydatkowania i zmierzać ich do ograniczenia.

W obu gminach głównym źródłem wydatków były zadania własne. W obu gminach udział zadań własnych zmniejszył się, ale wartość opisywanej pozycji na przestrzeni analizowanego okresu wzrosła. Największy udział w wydatkach z zadań własnych w obu gminach wykazywał dział oświata i wychowanie oraz administracja publiczna. Co za tym idzie wydatki w głównej mierze przeznaczone były na funkcjonowanie działalności przedszkoli, szkół podstawowych i gimnazjów oraz na wynagrodzenia pracowników gmin.

Porównując wydatki z obu gmin, można zauważyć, ze wartość wydatków w gminie Skulsk była niższa, aniżeli w gminie Wilczyn. W obu gminach przeważały wydatki z zadań własnych, a ich cel wydatkowania był podobny. Wydatki z zadań zleconych w obu jednostkach miały związek z wypłatą świadczeń społecznych. W odniesieniu do wydatków 
majątkowych, obie gminy inwestowały w infrastrukturę drogową, jednak gmina Skulsk dodatkowo zainwestowała w systemy informatyczne.

\section{Bibliografia}

1. Augustyniak M.,2012, Organizacja i funkcjonowanie rady gminy, Wolters Kluwer, Warszawa, s. 19

2. Denek E., Sobiech J., Wolniak J., 1997, Finanse Publiczne, Wydawnictwo Naukowe PWN, Warszawa, s. 54-55

3. Filipak B., Organizacyjne i funkcjonalne podstawy działalności samorządu terytorialnego w Finanse Samorządowe, Wydawnictwo Naukowe PWN, Warszawa 2006, s. 17

4. Kosikowski C. 2012, Regulacje prawne i zasady gospodarki finansowej j.s.t. pod redakcją C. Kosikowskiego i J.M. Salachny w Finanse samorządowe 580 pytań i odpowiedzi, Wolters Kluwer Polska Sp. z o. o., Warszawa 2012, s. 45, 50

5. Owsiak S., Finanse Publiczne współczesne ujęcie, Wydawnictwo Naukowe PWN, Warszawa, s. $304,308,310$

6. Rudowicz E., 2010, Budżet jednostki samorządu terytorialnego i procedura jego uchwalania pod redakcją M. Podstawki w Finanse, wydawnictwo Naukowe PWN, Warszawa, s. 177

7. www.bdl.stat.gov.p1/BDL/dane/teryt/kategoria/3395 [dostęp: 20.03.2019]

8. Ustawa z dnia 8 marca 1990 r. o samorządzie gminnym, Dz.U. $1990 \mathrm{nr} 16$ poz. 95

9. Ustawa Konstytucyjna z dnia 23 kwietnia 1935 r Dz.U. 1935 nr 30 poz. 227

10. Ustawa z dnia 27 sierpnia 2009 r. o finansach publicznych Dz.U. 2009 nr 157 poz. 1240 